\title{
Memory training and academic achievement in mathematics among basic seven students in Lagos metropolis
}

\author{
Ayoka Mopelola Olusakin and Akinyemi Anthony Ayeobasan \\ Department of Educational Foundations, University of Lagos, Akoka - Lagos. Nigeria. \\ Received 18 February 2014; Accepted 22 April, 2014
}

\begin{abstract}
The study investigates memory training and academic achievement in mathematics among basic seven students in Lagos metropolis who were randomly selected based on scoring after a conducted validated test on memory. T-test was used to test the three formulated hypotheses. The results revealed that there was significant difference in pre- and post-test mathematics achievement scores of the experimental group. There was significant gender difference in the post-test mathematics achievement score of students who went through memory training and also significant difference in the post-test mathematics achievement scores of the experimental and control groups.
\end{abstract}

Key words: Mathematics achievement scores, academic achievement, memory training, Lagos metropolis.

\section{INTRODUCTION}

We experience in our daily life that sometimes we want to recall name of a friend or some piece of information but fail to recall such information at that time but at different condition or occasion the name or information comes back more or less spontaneously. This phenomenon is called TOT (tip of the tongue) (Chauhan, 1998). Tip of the tongue shows how non availability of appropriate cues hinders retention. According to Chauhan (1998), forgetting is often a temporary rather than a permanent phenomenon. He opined further that forgetting is not like losing something but rather is more like being unable to find it. When cues that were present at the time of learning are not available at the time of recall, retention suffers. If stimulus terms are altered, recall will be reduces, forgetting therefore occurs because of failure in mechanism responsible for remembering. Memory provides a mental workspace that is used in many important activities in learning and is a pure measure of a child's learning potential. Memory deficits contribute to difficulties in learning and makeing poor academic progress among learners (Gathercole and Alloway, 2008).

llogu (2009) defines memory as the retention of information or response after the criterion has been reached. Memory according to Joni et al. (2010) is the mental faculty that allows us to retain information as well as recall experiences for a long time. Live science (2010) submitted that human memory is a highly complex neurological system and every individual's ability to encode, store, retrieve and interpret their own memory help to distinguish one person from the other. Memory could be measured generally by the three methods described by psychologists. These include:

*Corresponding a uthor. E-mail: a olusa kin@unila g.edu.ng.

Authors a gree that this artic le rema in pemanently open access under the terms of the Creative Commons Attribution Lic ense 4.0 Intemational Lic ense 
1. Recall

2. Recognition

3. Re-learning

Recall: This is used to measure memory of the students in the examination. It requires reproducing correctly what has been previously learned. Recall is simple to measure and the score is percentage correct.

Recognition: This is discrimination between seen or unseen. This is what we do in the process of taking multiple choice tests that is, recognizing the correct choice out of a number of choices.

Re-learning: This is the third technique of measuring retention instead of asking the subjects to recall or recognize material that have appeared in his post experience, we may ask him to relearn the material at some later stage. The difference between the number of trials or opportunities requires learning the material initially and the number of trials required to re - learn is then considered to be an index of retention. This index of retention is often referred to as a saving score.

Gathercole and Allow (2008) submitted that those children whose memory (working) abilities fall in the bottom 10\%, over $80 \%$ of them have substantial problems in either reading or solving mathematics or most commonly in both. Odogwu (2005) affirmed that students achievement in mathematics dwindle as years go by and many students seem to have negative attitude towards the subjects. According to Odogwu (2005), there is an equal and opposing forces drawing students to and away from mathematics bearing in mind the potential benefits of studying and excelling in mathematics, the students may approach mathematics with zeal and enthusiasm with effective conceptualization of mathematics terms. If appropriate teaching methods and psychological supports are given, this zeal can be translated to high achievement. Obioma (1991) and odogwu (1995) have both submitted that the expository method of teaching mathematics in schools have contributed to the poor performance of students in the subject. Odogwu (1995) further submitted that teaching method and teaching aids affect students' achievement and retention in mathematics.

\section{Memory training}

Every classroom teacher faces the problem of how to improve the retention of his students. Experimental studies suggest that we cannot eliminate forgetting completely, but we can take steps to lessen it. According to Chauhan (2009). The following methods could be used to improve retention or memory training.
1. Over Learning: It is an established fact that retention is greater when subject matter is well learned. The better something is learned, the better are its chances of survival despite interference due to learning other materials. Over learning is the term used to describe practice that continues after a perfect recall has been scored.

2. Meaningfulness and organization of subject matter: The most effective method to improve retention is the method of making the subject matter meaningful.

3. Use of mnemonic device: We are sometimes required to learn materials that come close to meaningless material in such instances it may be useful to use mnemonic devices to retain the material. Mnemonic systems when used by persons of capable visual memory can result in credible feats of memory. Information in the brain is deliberately transformed into a more meaningful organization to improve memory.

4. Self recitation: Psychologists are of the opinion that recitation is helpful in the process of retention. The experiment of Gates (1964) shows the greater effectiveness of self recitation. The materials his students learned consisted of both non - sense syllables and short biographies. Gates (1964) submitted that students performed best when they spent only $30 \%$ of their time reading the syllables and $80 \%$ of their time in self recitation.

5. Formation of clear concept: Another technique of training and improving memory which a teacher can use is to develop clear concepts with the help of various type of audio - visual material. Teacher should as well try to involve more than one senses in learning activity.

Of all the techniques listed above Chauhan (2009) stressed that "Self Recitation" is much more efficient way of retaining learned material, and more appropriate in memory training.

\section{Purpose of the study}

The purpose of this study is to investigate the effects of memory training on academic achievement in mathematics among basic seven students in Lagos metropolis. The study seeks to examine if variable such as gender has effects on retention.

\section{Research questions}

1. Will there be any significant difference in pre- and posttest mathematics achievement scores of the experimental group?

2. Will there be any significant difference due to post-test Mathematics achievement scores of the experimental group? 
3. Will there be any significant difference in post-test mathematics achievement score between the treatment and the control group?

\section{Research hypotheses}

The following hypotheses were formulated to guide the study:

1 There is no significant difference in pre- and post-test mathematics achievement scores of students who went through memory training (treatment group).

2 There is no significant gender difference in post-test mathematics achievement scores of students who went through memory training (treatment group).

3 There is no significant difference in post-test mathematics achievement scores between students who went through memory training (treatment) and the control group.

\section{METHODOLOGY}

The study is a quasi experimental design. The population consists of basic seven students in Lagos metropolis. A sample of 92 male and 100 female (192) students were used. The samples were selected using multi-stage sampling techniques. The data collection instrument was developed by the researcher and psychometrics properties of the instrument had 0.75 as reliability index established during the pilot study. The researcher adopted self-recitation techniques in memory training of selected basic seven students in Lagos metropolis. The researcher administered a pre-mathematics achievement test to the selected sample and commences treatment using self-recitation technique of memory training and administered a post - mathematics achievement test after four weeks of treatment.

\section{RESULTS AND DISCUSSION}

Hypothesis 1 which stated "There is no significant difference in pre and post test mathematics achievement scores of the treatment group" was tested with t-test statistical analysis and the result is as shown in Table 1.

From the table the calculated $\mathrm{t}$. ( $\mathrm{t}-\mathrm{cal}=2.661)$ is significantly greater than the critical $t(t-$ critical $=1.645)$ given 190 degree of freedom at 0.05 level of significance. As a result the null hypothesis which states that "There is no significant difference in pre and post test mathematics score of students who went through memory training is therefore rejected and the alternative hypothesis is accepted.

Hypothesis 2 which stated "There is no significant difference due to gender in post test Mathematics achievement scores of the treatment group" was also tested using t-test statistical analysis and the result is as shown in Table 2.

Table 2 shows that t-cal (2.015) > t-critical (1.645) at
0.05 level of significance, Null hypothesis two is therefore rejected and the alternative hypothesis is accepted "There is significant gender difference in post test Mathematics achievement score of students who went through memory training.

Hypothesis 3 which stated "There is no significant difference in post test mathematics scores of the experimental and control groups" was also tested with ttest statistical analysis and the result is as shown in Table 3. Table 3 shows that t-cal (2.012) $>\mathrm{t}$-cal (1.542) at 0.05 level of significance. Null hypothesis three is therefore rejected and the alternative hypothesis is accepted that is "There is significant difference in post test scores of the treatment and control group.

\section{DISCUSSION}

The findings of this study shows that "There is significant difference in pre and post test mathematics scores of students who went through memory training". The finding is in agreement with the submission of Odogwu (2001) that "Teaching methods and teaching aids affect students' achievement and retention in mathematics. The findings of the study also reveals that "There is significant gender difference in post-test Mathematics score of students who went through memory training. The findings conformed to the submission of Obe (1980), that "Memory factor among men occurs rapidly in rote learning especially memory for numbers, words and designs, and finally the findings shows that "there is a significant difference in post test mathematics scores of experimental and control group. This finding is in line with the submission of Anderson (2009) which states "that there is a correlation between the degree of retention and academic achievement.

\section{Counselling Implications}

1. Counseling as a helping relationship becomes relevant in providing awareness to teachers of Mathematics that the expository method of teaching Mathematics have not seem to improve Mathematics achievement.

2. Counseling should be organized for teachers of Mathematics in the basic schools on the need to improve the retention level of learners.

3. Counseling should be one the medium of awareness to teachers that "working memory training" has been found to improve fluid intelligence in normal adults.

4. Counseling should be organized for both teachers and students of Mathematics on how Mathematics could be used to increase students' store of knowledge.

5. There is a need for counseling clinic to be established in each of the schools in Lagos Metropolis and to be manned by professional counselors to enhance effectiveness. 
Table 1. T-test statistical analysis of the Pre- and post- test mathematics achievement scores of the treatment group.

\begin{tabular}{lccccc}
\hline Treatment group & $\mathbf{N}$ & Mean & SD & Tcal & Tcrit \\
\hline Pre test & 192 & 11.00 & 6.51 & & \\
Post test & 192 & 16.20 & 8.42 & 2.661 & 1.645 \\
\hline
\end{tabular}

Significant at 0.05 .

Table 2. T-test statistical analysis of the post- test mathematics achievement scores of the treatment group (Male and female).

\begin{tabular}{lcccccc}
\hline Variable & $\mathbf{N}$ & Mean & S.D & Df & t-cal & t-critical \\
\hline Male & 92 & 16.00 & 2.54 & & & \\
Female & 100 & 10.10 & 2.06 & 190 & 2.015 & 1.645 \\
\hline
\end{tabular}

Significant at 0.05 .

Table 3. T-test statistical analysis of the post- test mathematics achievement scores of the experimental and control groups.

\begin{tabular}{lccccc}
\hline Group & Mean & S.D & Df & t-cal & t-critical \\
\hline Treatment & 16.20 & 3.200 & & & \\
Control group & 8.01 & 2.120 & 190 & 2.012 & 1.542 \\
\hline
\end{tabular}

Significant at 0.05 .

6. Counseling should be used to spread the gospel that enhancement of working memory capacity could lead to attention and improvements in daily cognitive functioning.

\section{CONCLUSION}

The result of this study support the literature previously cited. It concluded that significant difference exist in pre and post test mathematics score of students went through memory training similarly "There is a significant gender difference in pre and post test mathematics achievement scores of students who went through memory training and finally significant difference exist in post test mathematics scores of the experimental and the control group.

\section{RECOMMENDATIONS}

This paper is of the opinion that the counselors in Nigeria with the present vibrant field of professional activities in consonance with the findings of this study should make spirited efforts in finding solutions to the problems confronting effective teaching and learning of mathematics. Since mathematics occupies a central place in pre-tertiary curricular and mathematics as a discipline helps to develop both scientific and logical thinking of students and their ability to imagine, rationalize and manipulate accurately. There is also a need to meet the basic need of teachers, especially mathematics teachers therefore the federal government should introduce welfare package or packages that will guarantee good living conditions.

\section{Conflict of Interests}

The author(s) have not declared any conflict of interests.

\section{REFERENCES}

Anderson BD (2009) Memory Improvement Techniques Ohio USA: Hillary Publishers.

Chauhan, S. S. (2009). Advance Educational Psychology of Human Learning. Changai: Chao Publishers.

Chauhan, S. S. (1998). Advance Educational Psychology. Changai: Chao Publishers.

Gathercole SE, Alloway TP (2008). Working memory and learning: A practical guide for teachers. London: Sage Publications.

llogu GC (1999). Theories of motivation and student learning paper presented at Conference of Nigeria Academy of Education in Uturu Nigeria. 
Joni H, Gathercole SE, Dunning DL (2009). Adaptive training leads to sustained enhancement of poor working memory. Live Science New York: Developmental Science Publishers. http://www.mrccbu.cam.ac.uk/wp-content/uploads/2013/09/Holmes-Dev-Sci.pdf

Obioma EO (1991). A study of the attitude of some Nigerians science students toward science and science teaching. J. Sci. Teachers Assoc. Nig., 22(2): 27-33.

Odogwu HN (2001). The effect of mastery learning on students' achievement and retention in Mathematics Lagos Educ. Rev. J. 2534.
Odogwu AC (2005). An Introduction to Vocational and Technical Education in Nigerian Schools and Colleges, Owerri: Nigeria Wisdom People Publishers.

Odogwu HN (1995). The effect of laboratory approach the performance and retention of different ability groups in ' 2 ' and ' 3 ' dimensional geometry. J. Stud. Curriculum 59:1-2. 